UDC 616-036.22: 615.5

DOI: $10.21668 /$ health.risk/2019.4.13.eng

\title{
DESCRIPTION OF BIOLOGIGAL FACTOR IN OCCUPATIONAL ENVIRONMNET OF MEDICAL ORGANIZATIONS THAT CAUSES RISKS OF HOSPITAL-ACQUIRED INFECTIONS
}

\author{
G.G. Badamshina ${ }^{1,2}$, V.B. Ziatdinov ${ }^{1,2}$, L.M. Fatkhutdinova ${ }^{2}$, B.A. Bakirov ${ }^{3}$, \\ S.S. Zemskova ${ }^{1}$, M.A. Kirillova ${ }^{1}$
}

${ }^{1}$ Center for hygiene and epidemiology in Republic of Tatarstan, 13a Sechenova Str., Kazan', 420061, Russian Federation

${ }^{2}$ Kazan State Medical University, 49 Butlerova Str., Kazan', 420012, Russian Federation

${ }^{3}$ Bashkir State Medical University, 47 Zaki Validi Str., Ufa, 450008, Russian Federation

There is a pressing issue related to biological factors that influence medical workers' health and cause risks of hospital-acquired infections including those occurring among patients. Given that, we applied conventional techniques to perform microbiological examinations aimed at detecting and identifying microorganisms that circulate in the air inside hospitals. Microorganisms detected in the air in areas where medical personnel performed their working tasks were identified with chromogenic nutrient media and microbiological analyzers. To fully characterize microorganisms, we performed certain tests that allowed determining how sensitive the detected strains were to common antibacterial preparations.

As a result, we revealed that priority strains detected in the air inside medical organizations were those belonging to Staphylococcaceae and Micrococcaceae families. These microorganisms caused high risks of purulent septic infections. We also detected bacteria that belonged to normal human microflora such as Acinetobacterspp. and Streptococcusspp., as well as gram-negative bacteria, notably Stenotrophomonasmaltophilia, Ochrobacteriumspp., Pantoeaspp., and Pausterellaspp.

Staphylococcusspp. and Micrococcusspp. turned out to be resistant to oxacillin and erythromycin; gram-negative bacteria, to ceftazidime and amikacin; non-fermentative bacteria and Enterobacteriaceae family, to a combination of antibacterial preparation. It proves there is a necessity to examine qualitative properties of biological factors existing in medical organizations. We revealed that Streptococcusspp. were strongly resistant to ampicillin, clindamycin, imipenem, and cefepime; Acinetobacterspp., strongly resistant to cephalosporin (ceftazidime, cefepime), and they were moderately resistant to monobactam (aztreonam); Stenotrophomonasmaltophilia, to ceftazidime and aztreonam, and in certain cases, to cefepime, amikacin, imipenem, gentamicin, and ciprofloxacin; Ochrobacteriumspp., to cefepime, aztreonam, ciprofloxacin, amikacin, gentamicin, imipenem, and ceftazidime; Pantoeaspp. and Pausterellaspp. tended to have various resistance. All it means that the given strains circulating in the air inside medical organizations are more resistant than they are considered to be according to literature data.

Key words: microorganisms, air, biological factor, medical workers, resistance to antibiotics, microbiological examinations, antibiotics, medical organizations, hospital-acquired infections, resistance of microorganisms.

(C) Badamshina G.G., Ziatdinov V.B., Fatkhutdinova L.M., Bakirov B.A., Zemskova S.S., Kirillova M.A., 2019

Gul nara G. Badamshina - Candidate of Medical Sciences, Head of the Microbiological Research Unit, Assistant lecturer at the Microbiology Department (e-mail: ggbadamshina@yandex.ru; tel.: +7 (843) 221-90-91; ORCID: https:// orcid.org/0000-0003-0088-6422).

Vasil B. Ziatdinov - Doctor of Medical Sciences, Chief Medical Officer (e-mail: fguz@16.rospotrebnadzor.ru; tel.: +7 (843) 221-90-90; ORCID: https://orcid.org/0000-0001-8029-6515).

Liliya M. Fatkhutdinova - Doctor of Medical Sciences, Professor, Head of the Department for Hygiene and Occupational Medicine (e-mail: liliya.fatkhutdinova@gmail.com; tel.: +7 (843) 221-90-90; ORCID: https://orcid.org/0000-0001-9506-563X).

Bulat A. Bakirov - Doctor of Medical Sciences, Professor, Head of Therapy Department (e-mail: bakirovb@gmail.com; tel.: +7 (347) 235-32-23; ORCID: https://orcid.org/0000-0002-3297-1608).

Svetlana S. Zemskova - Biologist oat the laboratory for bacteriological research (e-mail: zemskova_svetlana@mail.ru; tel.: +7(843) 221-79-13; ORCID: https://orcid.org/0000-0002-4095-0882).

Maria A. Kirillova - Biologist at the Department for Extremely Dangerous Infections Diagnostics (e-mail: mashkir.2015@bk.ru; tel.:+7(917)897-20-82; ORCID: https://orcid.org/0000-0001-8854-3402). 
Biological factor or a biological agent is a spectrum of microorganisms, pathogenic and opportunistic pathogenic bacteria, viruses, fungi, helminthes, protozoa, live cells, spores, etc., that exert adverse impacts on human health.

Microbiological monitoring over species of infectious agents and their resistance to antibacterial preparations that is performed in medical organizations is a reliable tool for assessing this biological factor and its qualitative properties; it should be done in order to determine its influence on medical personnel and to select proper antimicrobial therapy for patients in a specific medical organization [1].

In the past antibacterial preparations were frequently used rather irrationally (they were admitted to be prescribed to patients unreasonably in $50-70 \%$ in Canada, the USA, and Vietnam) [2]; antibiotics have been widely used in animal breeding; there has been an activation of adaptation mechanisms in inhospital bacterial communities as they mutate and transfer extrachromosomal in heritance factors to each other. All these events result in a persistent growth in resistance of various infectious agents and circulation of resistant strains in medical organizations causing occupational diseases among medical personnel and hospital-acquired infections among patients $[3,4]$.

Over the last years there have been a lot of changes in the structure of etiologically significant agents that cause infections, purulent diseases, and postoperative diseases; at present a number of such species is growing, and there are changes in microorganisms' properties that cause postoperative and postinjection complications; poly-etiologic diseases are becoming more and more widely spread among purulent and septic infections including hospital-acquired ones [1].
Circulation of resistance to antibiotics among opportunistic pathogenic in-hospital strains is becoming more and more pressing in spite of certain activities being accomplished at the moment $[5,6]$. Nowadays resistance to antibacterial preparations is considered to be an objective sign of genotypic and phenotypic peculiarities of a specific microorganism that causes a biological risk of hospital-acquired infections and occupational diseases [3].

Data and methods. Our goal was to examine properties of a biological factor existing in medical organizations. To do that, we accomplished microbiological examinations of air inside medical organizations in Kazan within state surveillance performed by the Federal Service for Surveillance over Consumer Rights Protection and Human Wellbeing. Air samples were taken prior to a working shift started and during it according to MG 4.2.2942-11 "Procedures for sanitarybacteriological examinations of environmental objects and air and for controlling sterility in medical organizations"1. Microorganisms extracted from air inside treatment rooms in different medical organizations were identified up to their species $(n=62)$. Identification was performed with chromogenic nutrient media produced in India and Spain and tests with microbiological analyzers produced in Czech Republic and France. We applied the disk diffusion test to check how sensitive microorganisms were to antibacterial preparations according to MG 4.2.1890-04 "Determining sensitivity of microorganisms to antibacterial preparations"

Results and discussion. Figure 1 shows the structure of microorganisms that were extracted from air inside medical organizations.

The given data make it obvious that microorganisms from Staphylococcus species prevailed in microflora existing in medical

\footnotetext{
${ }^{1}$ MG 4.2.2942-11. Procedures for sanitary-bacteriological examinations of environmental objects and air and for controlling sterility in medical organizations. Moscow, The Rospotrebnadzor's Federal Center for Hygiene and Epidemiology, 2011, 12 p.

${ }^{2} \mathrm{MG} 4.2 .1890-04$. Determining sensitivity of microorganisms to antibacterial preparations. Methodical guidelines. Moscow, The Federal Center for State Sanitary and Epidemiologic Surveillance of the RF Public Healthcare Ministry, 2004, 91 p.
} 

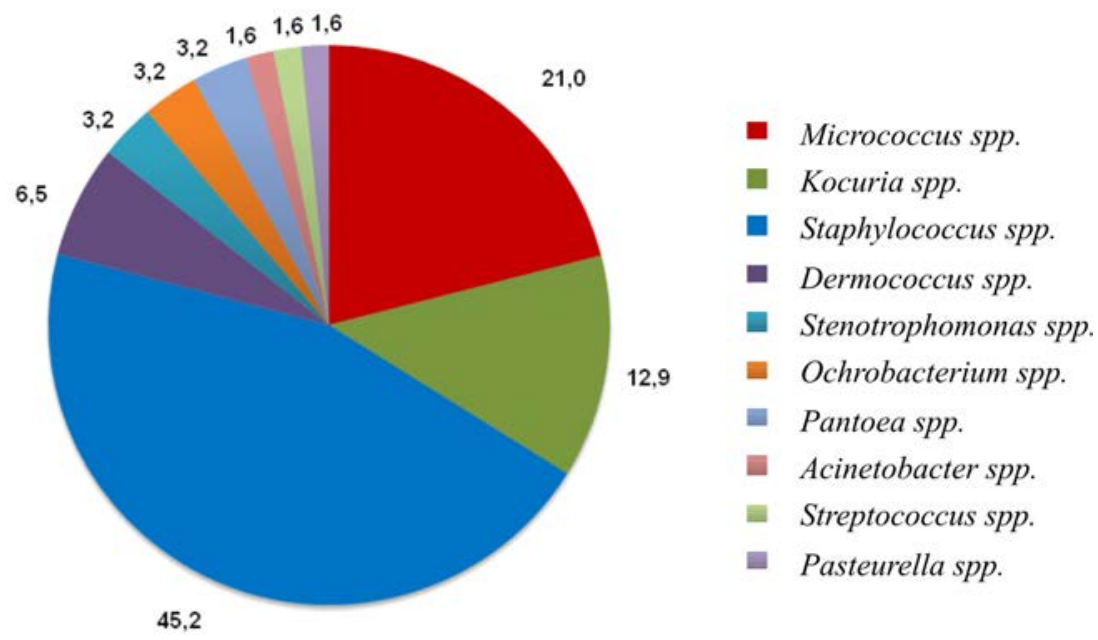

Figure 1. The structure of microorganisms that were extracted from air inside medical organizations $(\%)$

organizations in Kazan as there were totally 28 strains such as S.hominis $(11.3 \%)$, S. epidermidis $(9.7 \%)$, S. haemolyticus $(8.1 \%)$, S.saprophyticus (4.8\%), S.aureus $(1.6 \%)$ and some others $(6.4 \%)$. Data on Staphylococcus resistance were different for different medical organizations; in most cases such difference, as Afanasiev et al. think (2014), is due to a policy on how to apply antibacterial preparations.

When we characterize a biological factor in a medical organization, we should note that Staphylococcus spp. were resistant to Erythromycin (in $50 \%$ cases), Oxacillin (in $28.6 \%$ cases), and to Fluoroquinolones (up to $7.1 \%$ cases). It results in a high risk of infections caused by resistant strains including Methicillin-resistant Staphylococcus aureus (MRSA). Catalase-positive cocci belonging to this stem were the most sensitive to Vancomycin, Clindamycin, and Gentamicin (96.4-100\% cases). Our data are consistent with research works accomplished by most authors in the field who established that Staphylococcus spp. is resistant to Erythromycin and Oxacillin and sensitive to Vancomycin and Clindamycin [7-10]. Resistance to Oxacillin that has been examined by many experts is a marker showing that a Staphylococcus has a Penicillin-binding protein. There is an assumption based on research data that there are genetic data reservoirs for S.aureus coagulase-negative S.haemolyticus and S.epidermidis due to genes determining resistance to antibiotics being widely-spread in the population [3].

High resistance of Staphylococci to Oxacillin as a marker showing there is MRSA (Methicillin Resistant Staphylococcus Aureus) proves that all $\beta$-lactams are inefficient for treating infections caused by the given microorganisms and that it is necessary to develop more efficient therapeutic and anti-epidemic activities accomplished in medical organizations $[1,10]$.

Together with Staphylococcus spp., bacteria from Micrococcaceae family accounted for a considerable share among detected microorganisms $(40.4 \%)$. Micrococcusspp., that are frequently extracted from objects located inside medical organizations according to foreign experts [11-13], in all cases were sensitive to Ciprofloxacin and Clindamycin, not so frequently to Vancomycin, Levofloxacin, and Gentamicin (in $92.3 \%$ cases), and Erythromycin $(84.6 \%)$ and they were resistant to Oxacillin (69.2\% strains). This fact proves that microflora circulating inside medical organizations is normal and highly resistant to Oxacillin; it requires further investigations of biological risks related to infections caused by Micrococcusspp.

There are representatives from Kocuriaspp. family that, in foreign researchers' opinion, cause catheter-associated endocarditic, urinary tract infections, peritonitis, and other 


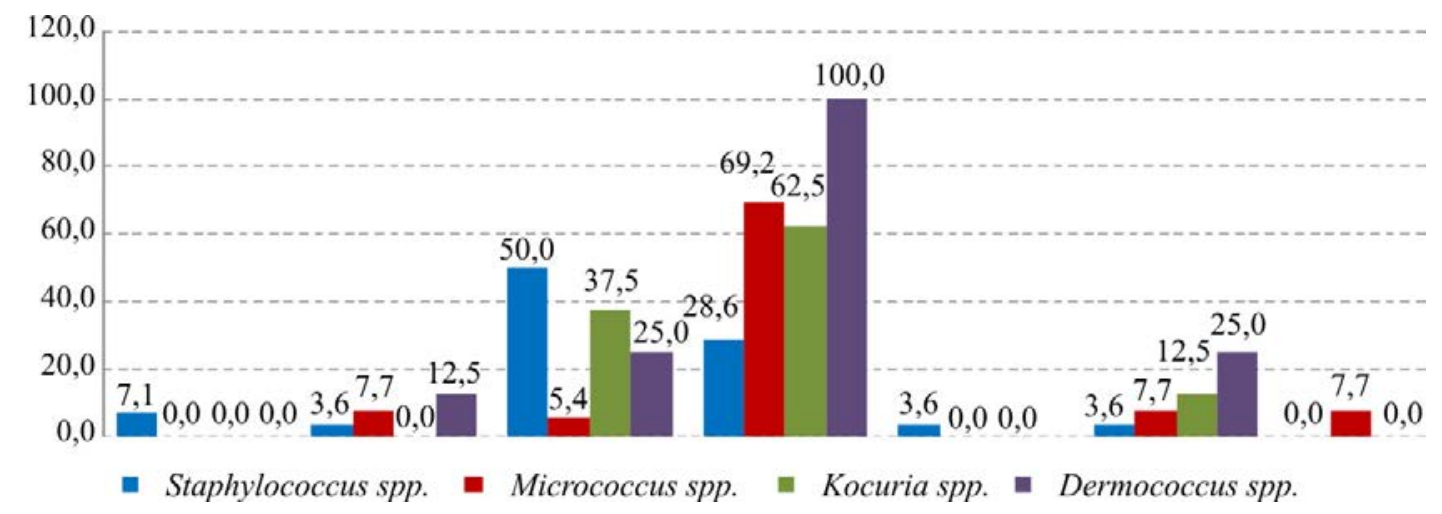

Figure 2. Specific weight of certain microorganisms' strains extracted from air that are resistant to antibacterial preparations (\%)

purulent and septic infections and are resistant to [14-16] Fluoroquinolones, Tetracycline, Oxacillin, and Cefazoline and intermediately resistant to Cefotaxime [17]; in our research they turned out to be the most resistant to Oxacillin (62.5\% cases), Erythromycin (37.5\% cases), and were rarely resistant to Fluoroquinolones (12.5\% to Levofloxacin). Occurrence of Oxacillin-resistant strains inside hospitals creates a biological risk of infections caused by Methicillin-resistant microorganisms.

Other bacteria from MicrococcaceaeDermacoccusspp. family extracted from air in 4 cases were also the most resistant to Oxacillin (resistance in all 4 cases), Erythromycin (in 1 case), and Levofloxacin (in 1 case). Data on Dermacoccus being sensitive to antibiotics are rarely found in literature sources available to us; however, there was a research work accomplished in Poland (2003) where the author showed that bacteria from this stem were resistant to Erythromycin [18].

Similar to other researchers' results, Streptococcusmitis, extracted from air in one case, was resistant to Ampicillin, Clindamycin, Imipenem, and Cefepime and sensitive to Vancomycin and Levofloxacin [3, 7]. As per data acquired by Afanasiev et al (2014), various resistances to Penicillin preparations as well as to Cephalosporin develop in Streptococcus due to lower affinity of Penicillinbinding proteins caused by mutations in bacteria's genome. It has been proven that interspecies transfer of genetic material occurring between commensal species of Streptococcus and S. pneumonia stems contributes to selection and creation of Penicillin-resistant strains of the latter [3].

Over the last years, gram-negative nonfermenting bacteria have been occupying the second place among agents causing different infections, including hospital-acquired ones, right after gram-positive cocci as it has been confirmed by our research [19].

When we characterize a biological factor that can cause HAI occurrence, we should note that gram-negative organisms that are a part of normal human microflora, such as Acinetobacterspp., extracted from air inside medical organizations, were sensitive to Ciprofloxacin $(57.1 \%)$, Amikacin, Imipenem, and Gentamicin, were moderately resistant to Monobactam (Aztreonam) and highly resistant to Cephalosporin (Ceftazidime and Cefepime). Research works performed by many authors prove that Acinetobacterspp. Extracted from human biological materials are the most resistant to Cephalosporin $[19,20]$. We didn't reveal resistance to Carbapenem and Monobactam in this stem though it was previously detected by various authors in $35.6 \%-70.5 \%$ bacteria belonging to various human biotopes $[1,6,9,19,21]$. Occurrence of resistant microorganisms from the given stem can cause infections both among medical personnel and patients.

Other gram-negative non-fermenting bacteria such as Stenotrophomonasmaltophilia that have been examined in multiple foreign research works are agents that cause hospital- 
acquired infections and are poly-resistant to antibiotics, including Cephalosporin [22]. In both cases in our research they turned out to be resistant to Ceftazidime and Aztreonam; in one case, to Cefepime, Amikacin, Imipenem, Gentamicin, and Ciprofloxacin. As opposite to the research accomplished by HuangY.W. et al. (2017), we revealed that in both cases this microorganism was sensitive only to Erythromycin [23].

Ochrobacteriumspp., that have low virulence for healthy people and high one for those with weak immunity [8, 24], were extracted from air in medical organizations in tow cases. One strain was resistant to antibacterial preparations in all cases (Cefepime, Aztreoname, Ciprofloxacin, Amikacin, Gentamicin, Imipenem, and Ceftazidime); the other was resistant only to Amikacin. Pantoeaspp. and Pausterellaspp. that cause various diseases have been given a lot of attention by researchers in Europe and America; in our research they were revealed to have different resistance to antibacterial preparations. In one case we detected that Pantoeaspp. was resistant to Ampicillin, Ceftazidime, Amikacin, and Imipenem $[25,26]$. The fact that the given strains are poly-resistant proves it is necessary to perform further investigations of this biological factor that exerts its influence on medical personnel and patients in hospitals.

\section{Conclusions}

1. Priority microorganisms extracted from air in medical organizations in Kazan in 2016 were bacteria from Staphylococcaceae $(45.2 \%)$ and Micrococcaceae ( $40.4 \%$ ) families;

2. Staphylococcusspp. and Micrococcusspp. were most resistant to Oxacillin $(28.6 \%-100.0 \%$ cases $)$ and Erythromycin (5.4-50.0\%). Gram-negative bacteria extracted from air in medical organizations in rare cases were most resistant to Ceftazidime (Acinetobacterspp., Stenotrophomonasspp., and Pantoeaspp.) and Amikacin (Ochrobacteriumspp and Pantoeaspp.); several non-fermenting bacteria and bacteria from Enterobacteriaceae family tended to be resistant to different combinations of antibacterial preparations;

3. Occurrence of strains that are resistant to various antibacterial preparations and circulate in air inside medical organizations causes a high biological risk of hospital-acquired infections and occupational diseases among medical personnel including infections caused by MRSA (Methicillin-resistant Staphylococcus aureus).

Funding. The research was not granted any financial support.

Conflict of interests. The authors declare there is no any conflict of interests.

\section{References}

1. Zharova L.V., Andreeva S.V., Bakhareva L.I., Egorova E.R., Titova M.V., Vlasova A.P. Characteristic of Species Composition and Antibiotic Sensitivity of Wound Infection in Different Departments of Surgery. Vestnik Chelyabinskogo gosudarstvennogo universiteta, 2015, vol. 376, no. 21, pp. 59-64 (in Russian).

2. Annual Epidemiological Report 2011. Reporting on 2009 surveillance data and 2010 epidemic intelligence data. Stockholm, European Centre for Disease Prevention and Control, 2011, 239 p.

3. Afanas'ev S.S., Karaulov A.V., Aleshkin V.A., Voropaeva E.A., Afanas'ev M.S., Nesvizhskii Yu.V., Egorova E.A., Aleshkin A.V. [et al.]. Monitoring of antibiotic resistance as an objective diagnostic and epidemiological criteria of infectious process. Immunopatologiya, allergologiya, infektologiya, 2014, no. 4, pp. 61-69 (in Russian).

4. Stokes H.W., Gillings M.R. Gene flow, mobile genetic elements and the recruitment of antibiotic resistance genes into Gram-negative pathogens. FEMS Microbiol. Rev., 2011, vol. 35, no. 5, pp. 790-819. DOI: $10.1111 /$ j.1574-6976.2011.00273.x

5. Gabrielyan N.I., Gorskaya E.M., Spirina T.S., Prudnikova S.A., Romashkina L.Yu. The study of antibiotic- and fagosensitivity of nosocomial strains bacteria isolated from transplanted patients. Vestnik transplantologii i iskusstvennykh organov, 2011, vol. 13, no. 3, pp. 26-32 (in Russian). 
6. Gonzalez-Villoria A.M., Valverde-Garduno V. Antibiotic-Resistant Acinetobacter baumannii Increasing Success Remains a Challenge as a Nosocomial Pathogen. J. Pathog., 2016, no. 2016, pp. 7318075. DOI: $10.1155 / 2016 / 7318075$

7. Bokonbaeva S.D., Apsamatova N.M. Antibiotic susceptibility etiologically significant microbial flora in acute obstructive bronchitis in children of early age. Vestnik KGMA im. I.K. Akhunbaeva, 2016, no. 6, pp. 104-108 (in Russian).

8. Al Tayyar I.A., Al-Zoubi M.S., Hussein E., Khudairat S., Sarosiekf K. Prevalence and antimicrobial susceptibility pattern of coagulase-negative staphylococci (CoNS) isolated from clinical specimens in Northern of Jordan. Iran J. Microbiol., 2015, vol. 7, no. 6, pp. 294-301.

9. Jahani-Sherafat S., Razaghi M., Rosenthal V.D., Tajeddin E., Seyedjavadi S., Rashidan M., Alebouyeh M., Rostampour M. [et al.]. Device-associated infection rates and bacterial resistance in six academic teaching hospitals of Iran: Findings from the International Nocosomial Infection Control Consortium (INICC). J. Infect. Public. Health, 2015, vol. 8, no. 6, pp. 553-561. DOI: 10.1016/j.jiph.2015.04.028

10. Panda R.K., Mahapatra A., Mallick B., Chayani N. Evaluation of Genotypic and Phenotypic Methods for Detection of Methicillin Resistant Staphylococcus aureus in a Tertiary Care Hospital of Eastern Odisha. J. Clin. Diagn. Res, 2016, vol. 10, no. 2, pp. 19-21. DOI: 10.7860/JCDR/2016/17476.7278

11. Abdollahi A., Mahmoudzadeh S. Microbial Profile of Air Contamination in Hospital Wards. Iranian Journal of Pathology, 2012, vol. 7, no. 3, pp. 177-182.

12. Sapkota B., Gupta G.K., Shrestha S.K., Pradhan A., Karki P., Thapa A. Microbiological burden in air culture at various units of a tertiary care government hospital in Nepal. Australas Med. J., 2016, vol. 9, no. 1, pp. 1-7. DOI: 10.4066/AMJ.2015.2558

13. Wolfe D.F., Sinnett S., Vossler J.L., Przepiora J., Engbretson B.G. Bacterial colonization of respiratory therapists pens in the intensive care unit. Respir Care, 2009, vol. 54, no. 4, pp. 500-503.

14. Brändle G., L'Huillier A.G., Wagner N., Gervaix A., Wildhaber B.E., Lacroix L. First report of Kocuria marina spontaneous peritonitis in a child. BMC Infect Dis., 2014, vol. 14, no. 1, pp. 3835. DOI: $10.1186 / \mathrm{s} 12879-014-0719-5$

15. Moreira J.S., Riccetto A.G., Silva M.T., Vilela M.M. [et al.]. Endocarditis by Kocuriarosea in an immunocompetent child. Braz. J. Infect. Dis., 2015, vol. 19, no. 1, pp. 82-84. DOI: 10.1016/j.bjid.2014.09.007

16. Sohn K.M., Baek J.Y., Kim S.H., Cheon S., Kim Y.S. Catheter-related bacteremia caused by Kocuriasalsicia: the first case. J. Infect. Chemother., 2015, vol. 21, no. 4, pp. 305-307. DOI: 10.1016/j.jiac.2014.11.005

17. Moissenet D., Becker K., Mérens A., Ferroni A., Dubern B., Vu-Thien H. Persistent bloodstream infection with Kocuria rhizophila related to a damaged central catheter. J. Clin. Microbiol., 2012, vol. 50, no. 4, pp. 1495-1498. DOI: 10.1128/JCM.06038-11

18. Szczerba I. Susceptibility to antibiotics of bacteria from genera Micrococcus, Kocuria, Nesterenkonia, Kytococcus and Dermacoccus. Med. Dosw. Mikrobiol., 2003, vol. 55, no. 1, pp. 75-80.

19. Gordinskaya N.A., Sabirova E.V., Abramova N.V., Karaseva G.N., Nekaeva E.S. Antibiotics sensitivity and molecular mechanisms of resistance of Acine to bacter baumanii, infectious agents of burn-wound infection. Meditsinskii al'manakh, 2015, vol. 40, no. 5, pp. 99-101 (in Russian).

20. Kishii K., Kikuchi K., Tomida J., Kawamura Y., Yoshida A., Okuzumi K., Moriya K. The first cases of human bacteremia caused by Acine to bacter seifertii in Japan. J. Infect. Chemother., 2016, vol. 22, no. 5, pp. 342-345. DOI: 10.1016/j.jiac.2015.12.002

21. Mitharwal S.M., Yaddanapudi S., Bhardwaj N., Gautam V., Biswal M., Yaddanapudi L. Intensive care unit-acquired infections in a tertiary care hospital: An epidemiologic survey and influence on patient outcomes. Am. J. Infect. Control., 2016, vol. 44, no. 7, pp. 113-117. DOI: 10.1016/j.ajic.2016.01.021

22. Brooke J.S. Stenotrophomonas maltophilia: an emerging global opportunistic pathogen. Clin. Microbiol. Rev., 2012, vol. 25, no. 1, pp. 2-41. DOI:10.1128/CMR.00019-11

23. Huang Y.W., Lin C.W., Ning H.C., Lin Y.T., Chang Y.C., Yang T.C. Overexpression of Sme DEF Efflux Pump Decreases Aminoglycoside Resistance in Stenotrophomonas maltophilia. Antimicrob Agents Chemother, 2017, vol. 61, no. 5, pp. e02685-e02716. DOI: 10.1128/AAC.02685-16 
24. Ashraf F. A case of Ochrobactrum anthropi-induced septic shock and infective endocarditis. R. I. Med. J. (2013), 2016, vol. 99, no. 7, pp. 27-28.

25. Seki M., Sakata T., Toyokawa M., Nishi I., Tomono K. A Chronic Respiratory Pasteurella multocida Infection Is Well-Controlled by Long-Term Macrolide Therapy. Intern Med., 2016, vol. 55, no. 3, pp. 307-310. DOI: 10.2169/internalmedicine.55.4929

26. Yamada K., Kashiwa M., Arai K., Satoyoshi K., Nishiyama H. Pantoeacalida bacteremia in an adult with end-stage stomach cancer under inpatient care. J. Infect. Chemother., 2017, vol. 23, no. 6, pp. 407-409. DOI: 10.1016/j.jiac.2017.01.001

Badamshina G.G., Ziatdinov V.B., Fatkhutdinova L.M., Bakirov B.A., Zemskova S.S., Kirillova M.A. Description of biologigal factor in occupational environmnet of medical organizations that causes risks of hospital-acquired infections. Health Risk Analysis, 2019, no. 4, pp. 122-128. DOI: 10.21668/health.risk/2019.4.13.eng

Received: 26.07 .2019

Accepted: 27.11.2019

Published: 30.12.2019 